\title{
Metodologia para definição de tipologias de políticas públicas, para entender a elaboração, implementação e avaliação
}

Cláudio Machado Maia ${ }^{1}$

Johnny Luiz Grando 2

\section{Resumo}

O presente artigo discute os vários elementos e estágios presentes em uma matriz de tipologias de políticas públicas, possibilitando a elaboração de um guia para os formuladores, implementadores e avaliadores dessas políticas, auxiliando na seleção daquela que melhor se ajusta na resolução de um problema estratégico, e, consequentemente, sua inclusão em uma agenda pública. Este estudo se insere no debate acerca da complexidade existente nas interações entre instituições, no jogo de poder e no nível de interesse dos atores, a partir da consideração de que o processo de formulação de políticas públicas, em suas fases de elaboração, implementação e avaliação, acontece de forma sistêmica, sendo que os modelos selecionados e utilizados nesses processos podem incluir ou excluir os atores beneficiados. $O$ trabalho teve como objetivo a interpretação de tipologias de políticas, por meio de uma fonte de consulta para o entendimento de como essas políticas são desenvolvidas. Em relação aos procedimentos metodológicos, partiu-se de uma breve revisão sobre o tema, seguida do estudo dos procedimentos de elaboração, implementação e avaliação. Coletados os dados de bases teóricas, foram desenvolvidas as interpretações, buscando-se o embasamento para a construção do roteiro que norteia o processo de formulação de políticas públicas. Na sequência, elaborou-se um roteiro na forma de uma matriz tipológica, permitindo a compreensão da importância e do condicionamento que as instituições - bem como a sua estrutura e cultura organizacional - têm na configuração dos principais elementos de uma decisão política, com vistas ao desenvolvimento socioeconômico.

Palavras-chave: Tipologia. Políticas Públicas. Formulação. Implementação. Avaliação.

\section{Abstract}

This article discusses the various elements and present stages in an array of public policy typologies, enabling the development of a guide to the makers, implementers and policy evaluators, assisting in selecting what better type fits in solving a problem

\footnotetext{
${ }^{1}$ Doutor em Desenvolvimento Regional. Professor do Programa de Pós-Graduação em Políticas Sociais e Dinâmicas, da Universidade Comunitária da Região de Chapecó (Unochapecó). claudiomaia.dr@hotmail.com

2 Economista. Mestre em Políticas Sociais e Dinâmicas Regionais. Professor da Universidade Comunitária Regional de Chapecó (Unochapecó). johnny@unochapeco.edu.br
} 
strategic and hence their inclusion in a public agenda. This study is part of the debate about the existing complexity of the interactions between institutions, the power play and the level of interest of the actors, from the consideration that the process of policy formulation in their design, preparation, implementation and evaluation, happen systemically, where the selected models and used in these processes can include or exclude the beneficiaries actors. It aimed, interpretation of policy types, such as a source of information for understanding how policies are developed. Regarding the methodological procedures, it started with a brief review of the subject policy types, followed by the study of the development of procedures, implementation and evaluation. Collected data from theoretical basis, interpretations seeking the foundation for the construction of the public policy process script were developed. Following, elaborated a script in the form of a typological matrix, allowing the understanding of the importance and the conditioning of the institutions as well as its organizational structure and culture, play an important role in the configuration of the main elements of a policy decision, views to the socio economic development.

Keywords: Typology. Public Policy. Formulation. Implementation. Evaluation.

\section{Introdução}

O desenvolvimento do Brasil, historicamente, é marcado pela dependência de recursos socioeconômicos de curto e longo prazo, sobretudo, de instituições de financiamentos com fortes influências internacionais. A formulação e implementação de políticas públicas com vistas ao desenvolvimento local, em benefício de determinado segmento econômico ou social, encontra-se no discurso político que permeia projetos ou programas governamentais intrinsecamente ligados a interesses de parte da sociedade que dispõe de influência política ou econômica e que possui acesso a recursos financeiros em detrimentos de outros segmentos produtivos ou atores locais.

Cada indivíduo leva adiante seus afazeres econômicos tão bem quanto
pode. Seguramente suas próprias intenções nunca são realizadas com
perfeição ideal, mas, em última instância, o seu comportamento é mol-
dado pela influência exercida sobre ele pelos resultados de sua conduta,
de modo a adequar-se a circunstâncias que, via de regra, não mudam su-
bitamente. Se um negócio não pode nunca ser absolutamente perfeito em
qualquer sentido, pode, no entanto, com o tempo, aproximar-se de uma
relativa perfeição, considerando-se o mundo ao redor, as condições so-
ciais, o conhecimento do momento e o horizonte de cada indivíduo ou de
cada grupo (SCHUMPETER, 1982, p. 56).

O modelo de política pública, comumente utilizado, geralmente direciona e beneficia as oligarquias e as instituições, determinando a "regra do jogo", o que remete à importância das instituições no processo de desenvolvimento e definição dos modelos e regras para a sociedade, o que explica os incentivos de troca humana, seja política, social ou econômica. A partir de então, os estudos passaram a enfatizar o conceito de firma como uma organização em crescimento, com outros atributos dinâmicos além dos representados pelas curvas de custos e rendimentos, ou por um 
equilíbrio baseado nas decisões sobre preço e produção.

Segundo Reis (2003, p. 14), as perspectivas de igualdades de oportunidades, propostas através do desenvolvimento econômico relacionado à ordem produtiva, causam contextos de desigualdade difíceis de "postular" como uma sociedade civil de forma singular, uma vez que custos e oportunidades tão desiguais impõem novos desafios aos formuladores de políticas públicas, como, por exemplo, regulamentar a exploração dos recursos disponíveis por oligarquias localmente constituídas.

Em relação aos poderes locais, segundo Paulillo (2000), estes são configurados em redes e legitimados pelas regras, cultura e interações dos atores locais, onde, segundo Fialho (2010, p. 3), a formulação e a implementação de políticas públicas “[...] é o resultado de arranjos institucionais, construídos por organizações de interesses privados específicos, agendas públicas governamentais e não governamentais" e que refletem, em sua maioria, em privilégios aos interesses das oligarquias tradicionais, exploração dos meios e recursos locais em detrimentos aos demais atores que inicialmente deveriam ser os maiores beneficiados.

Segundo Arretche (2000), a elaboração de políticas públicas pode ser considerada um processo eminentemente político, uma vez que a existência de certos grupos sociais exerce pressões sobre os formuladores dessas políticas, na busca de verem seus interesses contemplados através da formação de agenda e abordagens que permitam analisar problemas sociais e políticos.

À complexidade 3 levantada pelos objetivos, do ponto de vista metodológico, acrescentam- se a dificuldade em delimitar uma análise das inter-relações entre as instituições públicas e privadas, a definição de conteúdo e o processo político ideal com vistas à aplicação de políticas que visem ao desenvolvimento e à proteção de grupos/atores vulneráveis, regulamentando os benefícios estendidos a determinados grupos em detrimentos aos demais atores, mas, principalmente, de interpretar a existência de contrapartidas que possibilitem minimizar os efeitos sociais gerados pela descontinuidade das atividades das instituições beneficiadas, diante de um cenário de incertezas.

A fundamentação dessa indagação justifica a relevância social deste artigo, sobretudo porque busca compreender as interações entre instituições públicas e privadas e atores sociais, no processo de formulação e implementação de políticas públicas, e sua importância está em apresentar uma abordagem analítico-interpretativa a partir das tipologias utilizadas na elaboração e implementação de políticas públicas. O estudo, elaborado a partir da literatura referenciada, serve como uma alternativa de entendimento para abordar e analisar os modelos e tipologias de políticas, explicando os fatos a partir de alguns pressupostos da ciência política, dos

\footnotetext{
${ }^{3}$ A dificuldade fundamental resulta da discrepância entre a capacidade cognitiva limitada do ser humano e a complexidade dos problemas políticos. Mesmo quando ampliada por meio de instrumentos, que vão da linguagem escrita aos computadores eletrônicos, a mente humana não pode abranger toda a complexidade da realidade social. De acordo com a formulação bastante conhecida, o chamado "princípio da racionalidade limitada", a capacidade de formular e resolver problemas da mente humana é muito pequena comparada com os problemas cuja solução é necessária para um comportamento objetivamente racional no mundo real - ou mesmo para uma aproximação razoável dessa racionalidade objetiva (LINDBLOM, 1981, p. 21).
} 
meios utilizados no processo de formulação de políticas públicas, trabalhando com a hipótese de que essas políticas são arranjos institucionais complexos, representadas através de estratégias ou programas governamentais.

Neste contexto, objetiva-se apresentar uma reflexão teórico-metodológica que possibilite caracterizar o contexto das relações estabelecidas no âmbito das interações entre as instituições e os atores envolvidos. A metodologia é uma revisão bibliográfica, à luz da ciência política, direcionada à construção do entendimento do processo de formulação e implementação de políticas públicas, a partir da identificação de tipologias.

\section{Procedimentos metodológicos}

A metodologia presente neste estudo é a de uma pesquisa exploratória, apresentando uma revisão bibliográfica sobre o processo de formulação e implementação de políticas públicas, a interação entre instituições, empresas e atores envolvidos. Os aspectos complementares desta abordagem seguem as características impostas pela ciência política e políticas públicas, procurando caracterizar a racionalidade da formulação e implementação, através do poder público, da política pública, a articulação na resolução dos conflitos gerados na distribuição de recursos, as ações governamentais e suas mediações políticas, as quais, dependendo da forma de implementação, podem apresentar resultados divergentes dos inicialmente propostos nas agendas.

De abordagem qualitativa, o estudo utiliza dados e informações bibliográficas, a Constituição Federal Brasileira, leis, decretos, normas e decisões administrativas, tanto governamentais como também estaduais e locais, e, junto a materiais de institutos de pesquisa e de informações disponibilizadas em bibliotecas e demais publicações sobre o tema em periódicos, revistas e congressos.

Ao desenvolver uma reflexão analítico-interpretativa, a pesquisa utiliza o método de abordagem histórico-comparativo, que, para Boaventura (2007), é utilizado na ciência política no sentido de orientar o entendimento das condições contextuais e sua pertinência em relação ao fenômeno em estudo, sua clareza e rigidez aos pressupostos metodológicos. Com base nesse método, busca-se compreender o processo histórico da formação das políticas públicas, as relações de integração entre as esferas pública e privada e os atores locais, com foco nos fatores exógenos e endógenos, para a coleta das informações e respectiva análise e formação de um modelo de formulação de políticas públicas.

Sobre os procedimentos técnicos utilizados no estudo, em relação à pesquisa bibliográfica, primeiramente foi feito um levantamento histórico dos trabalhos já realizados sobre o tema. Segundo, para contextualização teórica do objeto de estudo, foram levantados os conceitos, as tipologias e os elementos utilizados na elaboração, implementação e avaliação de políticas públicas. Nesse contexto, como marco teórico na realização deste estudo, foi considerada a obra de Deubel (2007), por se tratar de uma alternativa de reflexão que permite fundamentar o entendimento, sobretudo do contexto brasileiro, por trazer e adotar uma abordagem (re)interpretativa do processo de políticas públicas, as relações entre burocracia, estado e sociedade 
civil, vis-à-vis a formulação, a implementação e a avaliação.

Para análise e interpretação das informações, foi utilizada a dimensão cronológico-tópica, implicando a organização sequencial dos eventos, datas, etapas temáticas, lógica, operações e interações, funções e instituições, remetendo a uma comparação entre as diversas etapas de evolução das políticas públicas ao longo do tempo até os seus efeitos recentes. A organização das seções obedeceu ao critério de tópicos, estabelecendo a tendência de interpretação dos eventos para, consequentemente, chegar às considerações finais.

\section{Ciência política para entender o processo de política pública}

A estratégia de realizar uma revisão bibliográfica a partir da Ciência Política na qualidade de uma ciência social possibilita utilizar métodos e técnicas que podem envolver tanto fontes primárias quanto secundárias no estudo do funcionamento e da estrutura do Estado das instituições: comportamento e sistemas políticos, administração e gestão pública, regimes partidaristas, processos eleitorais e, principalmente, as formas de organizações sociais.

Segundo Creswell (2007), a revisão bibliográfica documenta o estudo, mostrando que as opiniões são sustentadas pelas fontes consultadas e, quando busca o "estado da arte", descreve o estágio atual da contribuição acadêmica em torno de um determinado assunto.

\footnotetext{
A expressão Ciência política pode ser usada em sentido amplo e não técnico para indicar qualquer estudo dos fenômenos e das estruturas políticas, conduzido sistematicamente e com rigor, apoiado num amplo e cuidadoso exame dos fatos expostos com argumentos racionais. Nesta acepção, o termo 'ciência' é utilizado dentro do significado tradicional como oposto a 'opinião'. Assim, 'ocupar-se cientificamente de política' significa não se abandonar a opiniões e crenças do vulgo, não formular juízos com base em dados imprecisos, mas apoiar-se nas provas dos fatos (BOBBIO; MATTEUCCl; PASQUINO, 1998, p. 174).
}

Conforme Bonavides (2000, p. 52-63), política pública é o estudo da forma de atuação governamental em relação a determinados temas sociais e econômicos de interesse público, tais como salarial, educacional, de segurança, da relação entre os elementos constitutivos de Estado, nação, população, povo e soberania dos que estão no poder em relação aos demais cidadãos, ou seja, dos processos políticos do governo ou de qualquer outro sistema equivalente de organização humana que possua como objetivo garantir segurança, justiça e direitos civis, e permita compreender os aspectos econômicos nos quais uma estrutura social está embasada, fundamentando uma análise mais assertiva dos fenômenos e instituições políticas e suas formas de governar.

\subsection{Estudos correlatos}

Como área do conhecimento, o estado da arte da política pública teve origem nos Estados Unidos e se estendeu para a Europa. Em relação aos fundadores 
dessa área, Souza (2006) define quatro pesquisadores que se destacam. Laswell (1958) introduz a expressão de análise política pública (policy analysis), como forma de conciliar conhecimentos acadêmico e científico com a produção do governo e estabelecer o diálogo entre os atores envolvidos. Simon (1957) introduz o conceito de racionalidade limitada dos decisores públicos (policy makers), argumentando que a racionalidade dos decisores é sempre limitada por problemas como a informação incompleta ou imperfeita, tempo e interesse nas tomadas de decisões. Lindblom (1959; 1979) questionou a ênfase no racionalismo de Laswell e Simon, propondo a incorporação de outras variáveis à formulação e à análise de políticas públicas, tais como as relações de poder e a integração entre as diferentes fases do processo decisório, justificando por que as políticas públicas precisariam incorporar outros elementos à sua formulação e à sua análise além das questões de racionalidade, tais como o papel das eleições, das burocracias, dos partidos e dos grupos de interesse. E Eastone (1965), que contribuiu para a área ao definir a política pública como um sistema, ou seja, como uma relação entre formulação, resultados e o ambiente, onde as políticas públicas recebem inputs dos partidos, da mídia e dos grupos de interesse, que influenciam seus resultados e efeitos.

Em relação às políticas públicas nacionais, Souza (2003) relaciona as contribuições de Melo (1999) com o estado, governo e políticas públicas; Faria (2003) e a importância das ideias e do conhecimento; Batley (1999) e seu trabalho empíricoteórico sobre a reforma do setor público com base na teoria do "agente principal"; Arretche (2003), que, em seu dossiê sobre políticas públicas, examina o governo em "ação" assim como suas políticas que, em média, uma vez aplicadas, resultam em direções divergentes às inicialmente propostas pelos formuladores, onde vários fatores contribuíram para a visibilidade desta área:

O primeiro foi a adoção de políticas restritivas de gasto, que passaram a dominar a agenda da maioria dos países, em especial os em desenvolvimento. A partir dessas políticas, o desenho e a execução de políticas públicas, tanto as econômicas como as sociais, ganharam maior visibilidade. 0 segundo fator é que novas visões sobre o papel dos governos substituíram as políticas keynesianas do pós-guerra por políticas restritivas de gasto. Assim, do ponto de vista da política pública, o ajuste fiscal implicou a adoção de orçamentos equilibrados entre receita e despesa e restrições à intervenção do Estado na economia e nas políticas sociais. Esta agenda passou a dominar corações e mentes a partir dos anos 80, em especial em países com longas e recorrentes trajetórias inflacionárias como os da América Latina. O terceiro fator, mais diretamente relacionado aos países em desenvolvimento e de democracia recente ou recém - democratizados, é que, na maioria desses países, em especial os da América Latina, ainda não se conseguiu formar coalizões políticas capazes de equacionar minimamente a questão de como desenhar políticas públicas capazes de impulsionar o desenvolvimento econômico e de promover a inclusão social de grande parte de sua população (SOUZA, 2006, p. 20).

Por se tratar de uma nova perspectiva de análise do "governo em ação", a disciplina Análise de Políticas Públicas é uma confluência de vários enfoques.

Segundo Deubel (2007), a ciência política tradicional considerava, nos anos 
50 e 60, que as políticas públicas (policies) eram variáveis dependentes da atividade política (politics), cujo foco de interesses eram os resultados da participação eleitoral, e, por definição, as políticas públicas não eram mais do que o resultado das ações governamentais representando seus partidos políticos. $O$ interesse do estudo das políticas públicas como um "produto" (policy) da atividade política (politics) foi efetivado através de especialistas que buscavam auxiliar os formuladores de políticas a encontrar respostas a uma implementação eficiente e eficaz dessas políticas sob o enfoque de uma metodologia denominada de ciência política (policy science).

Essas definições remetem ao entendimento de que o Estado possui papel determinante na formulação das regras que definem as decisões sobre as agendas, tipos, elaboração de políticas públicas, e que fatores internos, como as instituições, e externos, como a globalização, podem gerar conflitos e influenciar nos resultados das suas implementações.

Estes fundamentos modelam uma construção elitista que, em sua maioria, exclui a participação do povo nas decisões políticas e abre lacunas que não são ocupadas pelo estado, devido ao fato de que o mesmo, muitas vezes, utiliza modelos de desenvolvimento não condizentes com as necessidades locais, sendo considerado um "intruso" pela própria comunidade beneficiada.

Conceitualmente, formulação e implementação de políticas públicas são definidas pela soma das atividades do governo, que escolhe o que fazer e o que não fazer, resultando em arranjos institucionais fomentados por organizações de interesses privados de determinados segmentos econômicos e agendas públicas, uma vez que "[...] não fazer nada em relação a um problema também é uma forma de política pública" (BACHRACH; BARATZ, 1962 apud SOUZA, 2006, p. 26).

A perplexidade perante a turbulência e a aparente não-governabilidade das políticas e da ação governamental, a sensação de 'desordem' que elas deixam perceber, não afetam apenas o cidadão. Os atores administrativos, políticos e seus analistas constatam igualmente a extrema complexidade das políticas públicas e as aparentes debilidades do Estado para cumpri-las (SARAVIA, 2006, p. 29).

Devido às complexidades relacionadas à formulação de políticas públicas, seu efeito é o resultado de mobilizações ${ }^{4}$ públicas, e sua implementação somente é efetivada através de regulamentações e legitimações jurídicas de interesses geralmente sociais ou econômicos, e, apesar das semelhanças em sua formação, o que se percebe é que as instituições governamentais são motivadas pelos jogos de poder, não são iguais ou homogêneas.

\subsection{Políticas públicas: conceito e tipologias}

Os processos de transformação percebidos em nível da economia global, como o desafio de implementar novos padrões de produção, consumo e distribuição

\footnotetext{
${ }^{4}$ Por lo tanto, las políticas públicas son el resultado de estas movilizaciones; por eso el análisis de las políticas públicas se constituye en una puerta de entrada para la compresión del Estado y de sus relaciones con la sociedad (DEUBEL, 2007, p. 25).
} 
de renda, utilizando novos meios de interação, produtividade e tecnologia, capazes de substituir modelos não mais sustentáveis socialmente, de um lado, e inviáveis economicamente, de outro, representam o novo desafio de minimizar as desigualdades naquilo que, segundo Furtado (1999, p. 74), reflete no contexto em que se insere uma "[...] economia cada vez mais globalizada, o que impossibilita a adoção uniforme de políticas públicas".

Em síntese, é necessário reexaminarmos as relações do Estado com o mercado, por um lado, e com a sociedade cível, por outro. No primeiro caso, parece-me que a área de políticas públicas compete, por exemplo, analisar como é que o Estado age e/ou poderia agir para assegurar a provisão de bens públicos que não são produzidos e/ou distribuídos pelo setor público (REIS, 2003, p. 13).

Em relação a um conceito sobre políticas públicas, Deubel (2007) inicia sua análise com base em três concepções. A primeira é a da política concebida como o âmbito do governo e das sociedades humanas (polity). A segunda, a da política como a atividade de organização e luta pelo controle do poder (politics). A terceira, a da política como designação dos propósitos e programas das autoridades públicas (policy).

Pode-se, então, resumir políticas públicas como o campo do conhecimento que busca, ao mesmo tempo, 'colocar o governo em ação' e/ou analisar essa ação (variável independente) e, quando necessário, propor mudanças no rumo ou curso dessas ações (variável dependente). A formulação de políticas públicas constitui-se no estágio em que os governos democráticos traduzem seus propósitos e plataformas eleitorais em programas e ações que produzirão resultados em mudanças no mundo real (SOUZA, 2006, p. 26).

Nas definições dos dicionários de ciências políticas, na identificação dos elementos que possibilitam a existência de políticas,

[...] encontram-se os seguintes componentes: a) institucional: a política é elaborada ou decidida por autoridade formal legalmente constituída no âmbito da sua competência e é coletivamente vinculante; b) decisório: a política é um conjunto - sequência de decisões, relativo a escolha de fins e/ou meios, de longo ou curto alcance, numa situação específica e como resposta a problemas e necessidades; c) comportamental implica ação ou inação, fazer ou não fazer nada; mas uma política é, acima de tudo, um curso de ação e não apenas uma decisão singular; d) causal: são os produtos de ações que tem efeitos no sistema político e social (SARAVIA, 2006, p. 31).

Portanto, em se tratando de políticas públicas, elas não existem sem uma construção social e um objetivo de investigação, possuem um campo específico de formulação e atuação, onde, mesmo que desenvolvidas por especialistas, não são isentas de arbitrariedade.

Segundo Deubel (2007), em relação às tipologias, uma forma de classificação das políticas é distingui-las a partir de um ou vários critérios e objetivos, como, por exemplo, a tipologia de Lowi (1972), que distingue quatro tipos de políticas: 
Theodor Lowi (1972) desenvolveu a talvez mais conhecida tipologia sobre política pública, elaborada através de uma máxima: a política pública faz a política. Com essa máxima, Lowi quis dizer que cada tipo de política pública vai encontrar diferentes formas de apoio e de rejeição e que disputas em torno de sua decisão passam por arenas diferenciadas. Para Lowi, a política pública pode assumir quatro formatos. O primeiro é o das políticas distributivas, decisões tomadas pelo governo, que desconsideram a questão dos recursos limitados, gerando impactos mais individuais do que universais, ao privilegiar certos grupos sociais ou regiões, em detrimento do todo. O segundo é o das políticas regulatórias, que são mais visíveis ao público, envolvendo burocracia, políticos e grupos de interesse. O terceiro é o das políticas redistributivas, que atinge maior número de pessoas e impõe perdas concretas e no curto prazo para certos grupos sociais, e ganhos incertos e futuro para outros; são, em geral, as políticas sociais universais, o sistema tributário, o sistema previdenciário e são as de mais difícil encaminhamento. O quarto é o das políticas constitutivas, que lidam com procedimentos. Cada uma dessas políticas públicas vai gerar pontos ou grupos de vetos e de apoios diferentes, processando-se, portanto, dentro do sistema político de forma também diferente (SOUZA, 2006, p. 28).

Essas tipologias, apesar da sua operacionalidade, não possuem uma aplicação muito evidenciada, devido à dificuldade em se determinar à qual categoria a política pertence, devido aos vários conceitos existentes.

\subsection{O Processo de formulação de políticas públicas}

A intervenção do Estado se faz necessária para garantir que as ações projetadas na formulação de uma política sejam implementadas, em função dos regimes 5 que utilizam para sua execução e dos vários instrumentos de intervenção entre os quais, segundo Deubel (2007), os mais utilizados são a) os instrumentos prescritivos, os quais buscam modificar o comportamento mediante uma obrigatoriedade, interdição estatal; b) os instrumentos de incentivos, os quais procuram obrigar um comportamento mediante o medo de uma sanção jurídica, ou induzir uma conduta mediante uma recompensa; c) os instrumentos de coordenação, cujos mecanismos devem ser obrigatoriamente desenvolvidos pelo Estado, em virtude da multiplicação das políticas públicas; d) os instrumentos de organização e de procedimentos, que definem como será organizada a realização de uma ação e quais procedimentos deverão ser utilizados; e) os instrumentos materiais, que definem como os bens e serviços públicos serão disponibilizados; f) os instrumentos de delegação a terceiros, que definem como a lógica neoliberal orienta o Estado a colaborar com instituições privadas ou não governamentais, a participar na execução das políticas públicas através da contratação de seus serviços.

\footnotetext{
${ }^{5}$ Es así como los regímenes autoritarios burocráticos privilegian las políticas de tipo reglamentario y infraestructura; los regímenes democráticos liberales prefieren las políticas redistributivas $y$, finalmente, los regímenes neo patrimoniales se quedan con las políticas distributivas y simbólicas (DEUBEL, 2007, p. 44).
} 
Independentemente, contudo, da existência de formas institucionalizadas de negociação via corporações e Estado, da diversidade de regimes políticos e sistemas eleitorais, e das características políticas que propiciam as bases da negociação, é inegável que é através da representação de interesses que se desenvolve atualmente a dinâmica de relacionamento político nas sociedades industriais modernas (LOBATO, 2006, p. 295).

Com base nestes modelos, no Brasil, é perceptível, segundo Souza (2006, p. 36), que o "novo gerenciamento público", através da experimentação de delegação de poder a determinados grupos sociais e/ou a grupos de interesses, é o compromisso assumido por determinados partidos políticos e a inserção de grupos sociais específicos na formulação de políticas, como, por exemplo, o orçamento participativo e fóruns comunitários com base em componentes e elementos presentes nos modelos de programa de políticas públicas.

Segundo Deubel (2007), programas de políticas públicas, cuja execução está fundamentada na disponibilidade de recursos financeiros, conceituam-se como instrumentos de coordenação fundamentados em relações causais, que possibilitam ao Estado alcançar seus objetivos, ou seja, atingir certas esferas da sociedade mediante uma organização de ações, regras e procedimentos na resolução de problemas específicos. Além disso, informação e transparência são os instrumentos que regularizam as implementações de políticas públicas e fornecem dados para comparações e análise de sua efetividade.

Já o plano de formulação de políticas públicas requer outras condições, que residem em um nível mais singular e são dadas pela organização sociopolítica específica, onde se formula a política pública. Nessa são relevantes as organizações sociais e políticas vigentes (regime político e padrão de organização da sociedade, as condições econômicas e, em maior ou menor grau, as condições tecnológicas e culturais (LOBATO, 2006, p. 301).

Segundo Saravia (2006), de forma resumida, é possível identificar as etapas de um processo de política pública, delineadas em sete momentos. O primeiro momento é o da agenda, determinando a necessidade, as prioridades e a legitimidade da intervenção pública. O segundo é o da elaboração, momento em que o problema é delimitado em função de uma comunidade. $O$ terceiro momento é o da formulação, que inclui seleção e especialização da alternativa mais conveniente e seus marcos (jurídico, administrativo e financeiro). O quarto momento é o da implementação, construída pelo planejamento, organização dos recursos. O quinto é o da execução, que representa o conjunto de ações destinadas a atingir as metas estabelecidas. $O$ sexto momento envolve o acompanhamento, que corresponde ao processo sistemático de "supervisão" das atividades e correções. E o sétimo é o da avaliação, que consiste na mensuração e análise dos efeitos produzidos na sociedade pelas políticas, sendo esta a que mais se desenvolveu atualmente.

Em relação aos modelos, componentes e elementos apresentados, o desenvolvimento de uma determinada política, para atingir certo padrão de "eficiência, eficácia e efetividade", passa pelo plano legal de sua formulação até sua implementação, que inclui uma série de relações e decisões. Portanto, existe uma seletividade 
em relação à formulação de políticas, onde alguns setores capitalistas são recompensados em detrimento aos demais, e essa fragilidade e dependência do governo em relação às instituições econômicas impediram a implantação efetiva de políticas sociais em países de economia retardatária, e, no Brasil, segundo Lobato (2006, p. 309), “[...] a incorporação de demandas sociais se deu de forma alienada, onde a universalização de bens sociais não passou pela cidadania, mas pela extensão de privilégios" às organizações que possuem maior poder nas decisões que configuram a política.

Toda a organização formal - sindicato, partido político, exército, empresa, etc. - tenta mobilizar recursos humanos e técnicos como meio para atingir seus fins. No entanto, os indivíduos dentro do sistema tendem a resistir a ser tratados como meios. Eles interagem como seres integrais, trazendo seus próprios e especiais problemas e propósitos; mais ainda, a organização está imersa numa matriz institucional e está, portanto, sujeita a pressões do seu próprio contexto, ao que um ajuste deve ser feito. Como resultado, a organização pode ser vista significativamente como estrutura social adaptativa, que enfrenta problemas que surgem simplesmente porque ela existe como organização em um meio ambiente institucional, independentemente dos objetivos (econômicos, militares, políticos) que provocaram sua existência (SARAVIA, 2006, p. 38).

Assim, em se tratando de sociedades sob o modelo de capitalismo, duas são as questões relacionadas a empresas e organizações estatais. A primeira, conceituase por critérios relevantes a sua estrutura administrativa, seu interesse e seu regimento interno, e está relacionada à acumulação de capital. A segunda se relaciona com o conceito de privilégio e legitimação do processo de acumulação da primeira. Nesse contexto, percebe-se que a racionalidade técnica e as argumentações são os elementos válidos que norteiam todos os discursos dos processos de formulação de soluções e tomadas de decisão para a implementação de políticas públicas.

\subsection{O Processo de implementação de políticas públicas}

A implementação das decisões públicas pode ser entendida como um problema administrativo e interpretada como um problema técnico de fácil execução, porém, dentro das perspectivas de análise em políticas públicas, essa é uma etapa fundamental e de difícil execução, pois até este momento, o da implementação, as decisões políticas são representadas apenas pelos discursos, e as palavras transformam-se em atos concretos, numa realidade palpável. 
Em outras palavras, a implementação consiste em fazer uma política sair do papel e funcionar efetivamente. Envolve os mais diversos aspectos do processo político-administrativo: desde a provisão de recursos do orçamento, formação de equipes, elaboração de minutas de projetos de lei, autorizando a realização de concursos para a contratação de servidores, elaboração de editais para a aquisição de bens ou contratação. Este processo não acontece automaticamente. Pois, independentemente da política, uma coisa é certa: o conhecimento dos objetivos e das normas só dá uma ideia do que de fato será feito pela(s) agências(s) implementadoras(s), e não informa quanto esforço será necessário para obter a cooperação e adesão dos diversos atores afetados pela política (RUA, 2009, p. 95).

A aplicação de regulamentos por diferentes entidades e em lugares distintos, a define com uma atividade de execução coletiva e que segue uma "regra do jogo" que impõe uma grande distância entre a decisão e a aplicação na prática, devido, principalmente, à ausência de estudos sobre a implementação em políticas públicas, os quais possibilitem a construção de técnicas de gestão para toda a cadeia hierárquica.

Segundo Deubel (2007), a primeira diferenciação clássica dos modelos de implementação está separada em duas categorias e definidas conforme sua função e aplicação prática: a) a primeira definição é chamada de top-down e representa a forma tradicional, que se desenvolve de cima para baixo e possui como principais postulados a hierarquia da autoridade, a diferenciação entre o universo político e o administrativo e o princípio da eficiência. Esse modelo considera que os problemas, na fase de execução, são problemas de coordenação e controle; b) a segunda definição se chama bottom-up e segue uma direção oposta à primeira, por tratar os enfoques críticos a partir de comportamentos de resolução concretos, em cada nível onde existe o problema, para se construir a política pública através de regras, procedimentos e estrutura organizacionais.

Apesar de todos os estudos realizados e modelos propostos para se analisar a implementação de políticas públicas, não existe um consenso sobre qual pode ser considerado mais adequado, ou utilizado como referência para uma aplicação prática, devido à dificuldade de se identificar quais são os elementos fundamentais de definição e implementação e as circunstâncias em que as ações são realizadas, ou seja, onde começa e onde termina uma implementação, bem como quais elementos são relevantes para a avaliação dessa implementação

Esta resolução parte do pressuposto de que os formuladores de uma decisão pública iniciam sua análise através da comparação dos custos para implementação, dividindo-os em: a) custos de negociação considerados baixos, quando os interesses são claros e existe um consenso ou respaldo dominante para uma solução em particular; caso contrário, o custo se eleva devido às negociações de interesses distintos, o que gera aumento do tempo para uma solução; b) custos da informação, que derivam da obtenção das informações necessárias para o conhecimento e a determinação de soluções possíveis ou da formulação de uma proposta de ação.

Segundo Ingram (1990 apud Deubel, 2007), para a implementação de uma política pública, é ideal que a administração encarregada de execução disponha de capacidade técnica, autoridade e acesso aos recursos que Ihe possibilitem realizar as tarefas que lhe são pertinentes e suportar pressões. 
Porém, na realidade, isso nem sempre é possível devido a dois problemas fundamentais. O primeiro está relacionado à vontade, interesse, capacidade e conhecimentos e recursos necessários para a implementação; o segundo, que as entidades responsáveis pela implementação sejam dependentes, dominadas ou controladas pelos beneficiados das políticas e colham os benefícios, sem nenhuma contrapartida a ser transferida aos responsáveis pela formulação e implementação dessas políticas, sendo necessário um marco flexível para sua execução.

\subsection{O Processo de avaliação de políticas públicas}

O desenvolvimento das práticas de avaliação do setor público coincide com a perda progressiva da legitimidade do Estado, sentida até mesmo em países desenvolvidos, onde o Estado intervencionista ou de bem-estar do século XX teve seus objetivos frustrados parcialmente, em função da realização parcial desses objetivos, apesar dos esforços realizados, cujos efeitos foram sentidos especialmente em suas políticas sociais. Para técnicas de gestão a serem implementadas, de um lado, apresenta-se o enfoque tradicional, legitimado na ação pública fundamentada em regras e procedimentos jurídicos, e, de outro, a legitimação da ação pública baseada em resultados.

Nesse sentido, o desenvolvimento da avaliação de políticas públicas não é legitimado unicamente nas deficiências do Estado, mas também nos atos de resolução dos problemas que busca resolver, controlar ou mitigar por meios de ações públicas, sempre complexas e incertas quanto aos meios, resultados e efeitos.

A avaliação profissional das políticas - o estudo, por especialistas, dos êxitos e falhas de um órgão governamental, na sua condição de uma política ou de um programa, ilustra alguns esforços feitos para elevar o nível de racionalidade do processo de decisão política. Idealmente, os estudos de avaliação proporcionam uma retroalimentação ('feedback'): revelando o que a última fase do processo político teve de certo ou errado, e orientam os passos seguintes (LINDBLOM, 1981, p. 16).

Existe uma grande variedade de modelos e tipos de avaliação de políticas públicas, que demonstram toda a complexidade da ação pública, seus objetivos e sua interpretação e podem ser definidos a partir de três perguntas-chave: qual é o momento de se avaliar (antes, durante ou depois); qual o objetivo e o tipo de avaliação e qual é a posição que ocupam os avaliadores do processo (DEUBEL, 2007).

Nesse contexto, as condições de formação e desenvolvimento de cada uma das diferentes fases ou etapas das políticas públicas, utilizadas para a construção da agenda pública e governamental, a formulação de políticas, a formulação de soluções e implementação de políticas públicas e seu processo de avaliação, contextualizando, também, as difíceis relações entre os meios social, científico, político e econômico, os atores públicos e privados e as ações governamentais em todas as fases das políticas públicas possibilitam concluir que a avaliação das políticas públicas segue sendo um processo político não isento de situações arbitrárias entre concepções divergentes, dentro de um processo também político de eleição entre sistemas 
de classificação de referências, conceitos, teorias e de modelos ou pontos de vista selecionados ou descartados, buscando legitimar as ações públicas.

\section{Entendendo o processo de formulação, implementação e avaliação de políticas públicas}

Vários conceitos levantados por diversos autores demonstram existir um consenso inicial de que as políticas públicas ocupam a agenda de muitas discussões, pelo fato de influenciar e direcionar a vida de todos os atores que são afetados pelos problemas e ações das esferas pública (policy) e política (politics), sendo que os resultados desses processos resultam em políticas públicas que se constituem em objeto específico de disputa qualificada, a qual envolve vários grupos sociais, com diferentes interesses formais, informais e relações de poder, na busca de uma resolução pacífica para o uso de bens públicos.

Ao definir qual a principal característica presente na sociedade contemporânea, em relação ao seu conjunto de indivíduos, Rua (2009), conclui ser o principal fator de análise a diferenciação social, que impõe aos seus membros, atributos diferenciados (gênero, renda, escolaridade, profissão, etc.), ideias e valores que desempenham papéis motivados pelos seus interesses e desejos, tornando a vida em sociedade complexa e conflitante em relação à resolução de problemas, através de dois meios possíveis de se administrarem os conflitos dentro de limites aceitáveis, a coerção e a política.

Em relação à coerção (que corresponde à ação de reprimir, corresponde à força exercida pelo Estado), o uso excessivo (desgastante para quem aplica) desta solução pode gerar dois problemas: o primeiro é a redução do seu impacto proposto, e o segundo é o aumento dos custos de transação ${ }^{6}$. Essas etapas apresentadas são formulação, implementação e avaliação de políticas públicas e seu estudo, possibilitando sintetizar um modelo de aplicação.

As etapas normalmente consideradas em matérias de políticas públicas formulação, implementação e avaliação -precisam de certo grau de especificação na América Latina. É necessário, por exemplo, distinguir elaboração de formulação. A primeira é a preparação da decisão política; a segunda, a decisão política, ou a decisão tomada por um político ou pelo Congresso, e sua formalização por meio de uma norma jurídica. A implementação também deve ser mais detalhada na América Latina. É necessário separar a implementação propriamente dita, que é a preparação para a execução (ou em outras palavras, a elaboração de planos, programas e projetos), da execução, que é pôr em prática a decisão política (SARAVIA, 2006, p. 32).

Estas diferenciações representam as diversas negociações presentes nas várias etapas que compõem um processo de formulação de políticas, as quais, na sua maioria, nem sempre são bem esclarecidas e podem ocorrer de forma simultânea no processo de produção de uma política.

O modelo de aplicação para a análise de políticas públicas, conceituado por

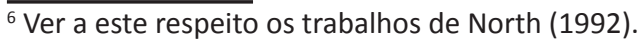


Deubel (2007) e Rua (2009) como "ciclo político" ou (policy cycle), propicia uma visão de como as decisões são - ou deveriam ser - realizadas, permitindo identificar os processos políticos, as estratégias, o comportamento e o envolvimento dos atores na decomposição da política pública, em uma série de etapas sequenciais, lógicas e sistemáticas, permitindo identificar, analisar e refletir os processos de políticas públicas, para uma decisão racional, onde, primeiramente, deve-se conhecer o problema, determinar seus valores e objetivos, analisar todas as soluções possíveis e, de posse de todas as informações necessárias, escolher qual a solução e os meios mais adequados para uma decisão acertada. Os governos que se utilizam deste modelo demonstram interesse e preocupação com a eficácia, a eficiência, a efetividade e a accountability (responsabilidade) de seus programas e ações, como um modo de alcançar os objetivos propostos e tornar públicos os resultados alcançados.

Em relação aos processos de elaboração, implementação e avaliação de políticas públicas, algumas características devem ser consideradas: a) este é um processo complexo, em constante mudança e de contínua interação, negociação e flexibilização em relação aos atores que colocam uma política em funcionamento; b) existe a necessidade dos responsáveis de se identificar, em cada fase, as considerações essenciais para a definição de um ciclo de políticas, a saber: o quê, quem, quando, como, onde, quanto e por que, definindo quem influencia ou é beneficiado no processo de uma política pública; c) o critério dominante utilizado na maioria dos processos é o econômico, que privilegia diretamente as atividades produtivas que promovam o desenvolvimento e a criação de capital tangível, desconsiderando a formação de capital social intangível; d) a base de considerações utilizada na maioria dos processos é predominantemente de racionalidade técnica; e) o processo de decisão é predominantemente interativo e envolve a participação de vários grupos de interesses diversificados, tornando-o complexo, e os resultados, em muitos casos, influenciam a continuidade, ou são distorcidos em seus objetivos iniciais; f) o poder político dos diferentes setores sociais, a regra do jogo e as instituições dentro do sistema político articulam e determinam as prioridades aos formuladores dessas políticas e quem realmente será beneficiado; g) os ajustes estruturais implementados em função das políticas com propósito de desenvolvimento, em sua maioria, desconsideram os ganhos sociais em sua fase inicial de elaboração; h) entre as políticas econômicas e sociais, a falta de coordenação se torna aparente, quando os indicadores sociais apresentam índices de estagnação, retrocesso, ou valores negativos em relação à efetividade dos resultados alcançados pelos programas e políticas destinadas a estes propósitos, como, por exemplo, saúde, educação, segurança e previdência pública.

Segundo Deubel (2007), a apresentação de diferentes modelos e enfoques, para a análise de implementação de uma política pública, é considerada uma difícil tarefa tanto para quem analisa quanto para quem a implementa, devido à capacidade de inovação, ao uso diversificado de recursos e ao nível de imprevisibilidade característicos da atividade política, que dificultam a decisão sobre o uso de um número reduzido de modelos que possam explicar uma implementação. Um modelo possível de contemplar os principais elementos utilizados como ferramentas de aná- 
lise é apresentado no Quadro 1.

Primeiramente, o tipo de política é selecionado pela característica de formulação, onde os objetivos determinam a classificação. Na segunda coluna, o tipo de política é determinado pelo enfoque de implementação (top-down ou botton-up, experimentos ou negociações). A terceira coluna classifica o tipo de política através dos critérios de avaliação a serem empregados. A quarta coluna é uma adaptação do modelo original, possibilitando classificar o tipo de política em função do seu custo, e a quinta coluna procura demonstrar quais fatores impactam na aplicação do modelo apresentado.

\section{Quadro 1 - Roteiro para o processo de formulação, implementação e avaliação de políticas públicas}

\begin{tabular}{|c|c|c|c|c|c|}
\hline $\begin{array}{l}\text { Tipo de } \\
\text { política }\end{array}$ & $\begin{array}{l}\text { Característica } \\
\text { de Formulação }\end{array}$ & $\begin{array}{c}\text { Enfoque de } \\
\text { Implementação }\end{array}$ & $\begin{array}{l}\text { Critério de } \\
\text { Avaliação }\end{array}$ & $\begin{array}{c}\text { Custos de } \\
\text { Implementação }\end{array}$ & $\begin{array}{c}\text { Variáveis } \\
\text { críticas de } \\
\text { Implementação }\end{array}$ \\
\hline Tipo 1 & $\begin{array}{l}\text { Objetivos } \\
\text { claros e } \\
\text { procedimentos } \\
\text { flexíveis }\end{array}$ & $\begin{array}{l}\text { Top - Down } \\
\text { clássico, } \\
\text { comando e } \\
\text { controle }\end{array}$ & $\begin{array}{l}\text { Realização dos } \\
\text { objetivos }\end{array}$ & $\begin{array}{l}\text { Custos de } \\
\text { negociação } \\
\text { baixo/custos } \\
\text { de informações } \\
\text { baixos }\end{array}$ & $\begin{array}{l}\text { Troca de } \\
\text { circunstâncias } \\
\text { externas ou em } \\
\text { torno de uma } \\
\text { política }\end{array}$ \\
\hline Tipo 2 & $\begin{array}{l}\text { Objetivos } \\
\text { abertos e } \\
\text { procedimentos } \\
\text { flexíveis }\end{array}$ & $\begin{array}{l}\text { Bottom up, por } \\
\text { retrocesso }\end{array}$ & $\begin{array}{l}\text { Criatividade } \\
\text { e liderança } \\
\text { administrativa } \\
\text { e capacidade } \\
\text { de inovação }\end{array}$ & $\begin{array}{l}\text { Custos de } \\
\text { negociação } \\
\text { altos/custos de } \\
\text { informações } \\
\text { baixos }\end{array}$ & $\begin{array}{l}\text { Liderança } \\
\text { administrativa } \\
\text { e respaldo de } \\
\text { políticos }\end{array}$ \\
\hline Tipo 3 & $\begin{array}{l}\text { Objetivos } \\
\text { clarose } \\
\text { procedimentos } \\
\text { precisos }\end{array}$ & $\begin{array}{l}\text { Experimentos e } \\
\text { reformulações }\end{array}$ & Aprendizagem & $\begin{array}{l}\text { Custos de } \\
\text { negociação } \\
\text { baixos/custos de } \\
\text { informações altos }\end{array}$ & $\begin{array}{l}\text { Capacidade } \\
\text { administrativa }\end{array}$ \\
\hline Tipo 4 & $\begin{array}{l}\text { Objetivos } \\
\text { claros e } \\
\text { procedimentos } \\
\text { flexíveis }\end{array}$ & Negociações & $\begin{array}{l}\text { Acordos e } \\
\text { respaldos }\end{array}$ & $\begin{array}{l}\text { Custos de } \\
\text { negociação } \\
\text { altos/custos de } \\
\text { informações altos }\end{array}$ & $\begin{array}{l}\text { Relacionamento } \\
\text { com os atores } \\
\text { beneficiados }\end{array}$ \\
\hline
\end{tabular}

Fonte: Deubel (2007), adaptado pelo autor.

Se a definição pela utilização de um modelo único em si já demonstra certa dificuldade, a análise sistemática de comparações entre o modelo padrão e os efeitos reais pode apresentar resultados de análises com significativas variações; conforme a visão adotada, muda a tipologia de política. A escolha não é neutra e deve ser feita conforme o tipo de política a ser adotada, analisada e diferenciada através de duas macroanálises: primeiramente, a econômica, através da formação de capital tangível, e, em segundo lugar, a ideológica, pelos ganhos obtidos na formação do capital intangível.

Embora as políticas públicas possam incidir sobre a esfera privada, elas não 
são privadas. Mesmo quando as entidades privadas participam efetivamente na sua elaboração e implementação, a participação está amparada em uma decisão pública, tomada por agentes governamentais embasados na autoridade do Estado. Conceitualmente, uma política pública demanda uma decisão política. Na prática, a maioria das decisões políticas não se transformam em uma política pública. Assim, determinar a existência de padrões de atuação, recorrentes de determinados formuladores e implementadores de políticas públicas e os reflexos das suas decisões sobre os demais atores, instituições, políticos e grupos econômicos, é o objetivo do modelo apresentado.

\section{Considerações finais}

Este estudo teve como objetivo geral apresentar uma abordagem analítica e interpretativa que possibilitasse caracterizar o contexto das relações historicamente estabelecidas nos âmbitos da formulação, implementação e análise de políticas públicas, entre as instituições pública e privada e os atores envolvidos nesse processo. O escopo de pesquisa foi orientado na busca da confirmação da hipótese de que as políticas públicas são arranjos institucionais complexos representadas através de estratégias ou programas governamentais, observado o fato de que a complexidade, na elaboração de modelos que melhor representem interações da vida real, impõe aos seus processos de elaboração um movimento contínuo de mudanças na resolução de problemas.

Identificou-se que, se este problema for de ordem estratégica e passar a configurar em uma agenda governamental, ele se torna um problema político que demandará uma política pública, porém o reconhecimento desse problema não significa uma garantia de sua implementação.

Com base na abordagem tradicional da Ciência Política, foram encontrados elementos consistentes para comprovar que a análise dos determinantes da tomada de decisão, em relação à solução de conflitos e à evidência da participação, aceitação e definição do papel de cada ator envolvido no processo, está voltada ao interesse dos atores que apoiam ou não a decisão de colocar em ação - ou não - essa política. O jogo de poder e as interações entre as instituições públicas e privadas em determinado jogo político, para se determinar qual o custo e quais os atores beneficiados ou excluídos, os retornos políticos e econômicos de curto, médio e longo prazo, a partir do momento de formação de uma agenda pública.

Dentre os modelos estratégicos analisados para a tomada de decisão, para entender o processo de formulação de políticas, a abordagem da Ciência Política mostrou ser um procedimento complexo, uma vez que a escolha do modelo e suas interpretações impõem uma diferença na metodologia de pesquisa, quando a análise da estrutura de poder é que realmente está coordenando o processo de elaboração de políticas.

Neste estudo, foram selecionados, primeiramente, o modelo racional de caráter normativo, que se supõe ser um processo racional, definindo que os problemas são técnicos e não políticos e consensuais, composto de atividades sistemáticas e desenvolvidas 
sob controle; e, segundo, o modelo incremental, o qual interpreta o processo de formulação como eminentemente político, com a participação, via jogo de interesses, de atores políticos em todas as fases, compreendendo a implementação como complexa, e a política, como resultado de um processo de concessões desenvolvidas em um ambiente de conflitos. Assim, a metodologia conceitual desses modelos mostrou-se mais adequada para conceituar e entender o processo político de formulação de políticas públicas e a necessidade da padronização de um modelo de referência.

Em relação às tipologias de políticas públicas, último elemento para fundamentação do problema proposto neste estudo, a metodologia utilizada para o sequenciamento das fases que compõem o processo de análise e elaboração de políticas, foi embasada no estudo realizado por Deubel (2007) como o modelo comumente utilizado na América Latina. Os arranjos institucionais, pertinentes ao processo de elaboração de políticas públicas, foram divididos em três fases: formulação, implementação e avaliação, o que possibilitou identificar a dualidade existente entre os modelos racional e incremental, utilizando seus pontos em comum, na verificação dos limites das interações entre poder, decisão e interesses no processo decisório quanto à definição dos objetivos e estratégias utilizados pelos formuladores em cada ciclo econômico estudado.

Neste processo, as fases são apresentadas de forma sucessiva, primeiramente, quando a política é formulada, a partir de um problema estratégico e da inclusão em uma agenda governamental, pelos tomadores de decisão, as quais podem ser decisões democráticas, participativas ou autoritárias, dentro de gabinete - no estilo top down ou bottom up -, do tipo racional ou incremental, influenciada pelo nível de poder ou interesse por parte dos atores envolvidos, detalhada ou incompleta, com objetivos e metas definidos ou não.

Enfim, em síntese, a importância deste estudo está relacionada à apresentação de uma metodologia que possibilita servir como ferramenta para entendimento do processo de elaboração de políticas públicas. A saber: formulação, implementação e avaliação, demonstrando que, embora complexo, o entendimento das relações institucionais, participação de atores, governança, imparcialidade, clareza de objetivos e metas, durante o processo de elaboração de políticas públicas, compreende o conjunto de fatores responsáveis em produzir os resultados, cuja avaliação de projeção e alcance indicará novas ações de direcionamento a serem realizadas para a correção de desvios de objetivos e metas.

Políticas públicas, neste contexto, representam um ciclo sistêmico e retroalimentado, em cujo processo de elaboração deverão constar novos padrões de funcionamento, como uso da democracia participativa em agendas públicas e formação de capital social. Além destes, há a discussão de soluções de modelos sociais, nas etapas de desenvolvimento de mercados, como formação, estabilização e transformação, possibilitando que novas iniciativas se constituam em processos contínuos de desenvolvimento socioeconômico. 


\section{Referências}

ARRETCHE, Marta Teresa da Silva. Estado Federativo e Políticas Sociais:

determinantes da descentralização. Rio de Janeiro: Revan; São Paulo: FAPESP, 2000.

Dossiê agenda de pesquisa em políticas públicas. Revista Brasileira de

Ciências Sociais, São Paulo, v. 18, n. 51, p. 7-9, fev. 2003.

BATLEY, Richard. The new management in developing coutries: introduction and Implications for policy and organizational reform. Journal of International Development, [S.1.], v. 11, p. 755 -765, 1999.

BOAVENTURA, Edivaldo M. Metodologia da pesquisa: monografia, dissertação, tese. 3 reimpr. São Paulo: Atlas, 2007.

BOBBIO, Norberto; MATTEUCCI, Nicola; PASQUINO, Gianfranco. Dicionário de política I. Brasília: UnB, 1998.

BONAVIDES, Paulo. Ciência Política. 10. ed. ver. atual. São Paulo: Malheiros, 2000.

CRESWELL, John. W. Projeto de Pesquisa - Métodos Qualitativo, Quantitativo e Misto. 2. ed. Porto Alegre: Bookman-Artmed, 2007.

DEUBEL, André-Noël Roht. Políticas Públicas: formulación, implementación y evaluación. 5. reimpr. Bogotá: Ediciones Aurora, 2007.

EASTONE, David. A Framework for Political Analysis. Englewood Cliffs: Prentice Hall. 1965.

FARIA, Carlos Aurélio Pimenta. Idéias, Conhecimento e Políticas Públicas: um inventário sucinto das principais vertentes analíticas recentes. Revista Brasileira de Ciências Sociais, n. 18, v. 51, p. 21-30, 2003.

FIALHO, Marco Antônio Verardi. Interfaces entre desenvolvimento rural, políticas públicas e atores sociais para o desenvolvimento territorial. Sociedade Brasileira de Economia, Administração e Sociologia Rural. Campo Grande. 2010. Disponível em: <http://www.sober.org.br/palestra/15/1258.pdf>. Acesso em: 13 jun 2014.

FURTADO, Celso. O longo amanhecer: reflexões sobre a formação do Brasil. 2. ed. Rio de Janeiro: Paz e Terra, 1999.

LASWELL. H.D. Politics: who gets what, when, how. Cleveland, New York Meridian Books, 1958.

LINDBLOM, Charles Edward. O Processo de decisão política. Trad. de Sérgio Bath. Brasília: UnB, 1981.

. Still Muddling, Not Yet Through. Public Administation Review, v. 39, p. 517-526, 1979.

. The Science of Muddling Through. Public Administration Review, v. 19,

p. 78-88, 1959. 
LOBATO, Lenaura. Algumas considerações sobre a Representação de Interesses no Processo de Formulação de Políticas Públicas. In: SARAVIA, Enrique. Introdução à teoria da política pública. Brasília: ENAP, 2006. p. 289- 313.

LOWI, Theodor. Four Systems of Policy, Politics, and Choice. Public Administration Review, v. 32, p. 298-310, 1972.

MELO, Marcus André. Estado, Governo e Políticas públicas. In: MICELI, S. (Org.). O que ler na ciência social brasileira (1970-1995). Ciência Política, São Paulo; Brasília, Sumaré/Capes, v. 3, p. 59-100, 1999.

NORTH, Douglass C. Custos de transação, instituições e desempenho econômico. Rio de Janeiro: Instituto Liberal, 1992.

PAULILLO, Luiz Fernando. Redes de Poder e Territórios Produtivos: indústria, citricultura e políticas públicas no Brasil do século XX. São Carlos: UFSCar, 2000.

REIS, Elisa P. Reflexões leigas para a formulação de uma agenda de pesquisa em políticas públicas. Revista Brasileira de Ciências Sociais, São Paulo, v. 18, n. 51, p. 11-14, fev. 2003.

RUA, Maria das Graças. Políticas públicas. Florianópolis: Departamento de Ciências da Administração/UFSC; Brasília: CAPES; UAB, 2009.

SARAVIA, Enrique. Introdução à teoria da política pública. Brasília: ENAP, 2006,

SCHUMPETER, J. Teoria do desenvolvimento econômico: uma investigação sobre lucros, capital, crédito, juro e o ciclo econômico. São Paulo: Abril Cultural, 1982.

SOUZA, Celina. "Estado do campo" da pesquisa em políticas públicas no Brasil. Revista Brasileira de Ciências Sociais. v. 18, n. 51, p. 15-20, fev. 2003.

. Políticas Públicas: uma revisão da literatura. Sociologias, Porto Alegre, ano 8, n. 16, p. 20-45, jul./dez. 2006.

SIMON, Herbert. Comportamento Administrativo. Rio de Janeiro: USAID, 1957. 